\title{
Steroid-responsive encephalopathy associated with autoimmune thyroiditis
}

INSERM

\section{Source}

INSERM. (1999). Orphanet: an online rare disease and orphan drug data base. Steroidresponsive encephalopathy associated with autoimmune thyroiditis. ORPHA:83601

Steroid-responsive encephalopathy associated with autoimmune thyroiditis (SREAT) is a rare, acquired, neurological disease characterized by encephalopathy associated with elevated antithyroid antibodies, in the absence of other causes. Clinical presentation varies from minor cog nitive impairment to status epilepticus and coma, and frequently includes seizures, confusion, speech disorder, memory impairment, ataxia and psychiatric manifestations. 